\title{
ARTE Y ALIENACIÓN EN BILBAO
}

\section{İñigo Varona Sánchez}

Universidad del País Vasco / Euskal Herriko Unibertsitatea. Doctorando Arte e Investigación en Arte Contemporáneo

\section{Resumen}

El capital entra en Bilbao por la cultura, la desindustrialización y ruinas industriales, dan paso a la construcción de una nueva urbe, tomando el espacio como valor de cambio, como producto en los que imponer el nuevo modelo de ciudad creativa neoliberal. En esta nueva ciudad, hábitat por antonomasia de las artistas, (a las que se nos aglutina en las denominadas clases creativas) ¿qué papel jugamos?, ¿tienen relación el arte y la cultura en los procesos de gentrificación en la capital vizcaína?

\section{Palabras clave: BILBAO; ESPACIO URBANO; GENTRIFICACIÓN; ARTE; ALIENACIÓN; CIUDADANISMO.}

\section{ART AND ALIENATION IN BILBAO}

\section{Abstract}

Capital enters Bilbao through culture, deindustrialization and industrial ruins, giving way to the construction of a new city, taking space as a value of change, as a product in which to impose the new model of neoliberal creative city. In this new city, habitat par excellence of the artists, (to whom we are grouped in the so-called creative classes) what role do we play? Do art and culture have a relationship in the gentrification processes in the Biscayan capital?

Keywords: BILBAO; URBAN SPACE; GENTRIFICATION; ART; ALIENATION; CITIZENSHIP

\footnotetext{
Varona Sánchez, Íñigo. 2018. "Arte y alienación en Bilbo [Art and alienation in Bilbao]“. AusArt 6 (2): 93-101. D0I:10.1387/ausart.20370
}

\section{AUSART}




\section{INTRODUCCIÓN}

En el siguiente artículo vamos a reflexionar y responder a la pregunta " ¿Es todavía posible hoy una crítica al sistema desde las prácticas artísticas?" tomando como marco específico de estudio la influencia de las prácticas artísticas y culturales en el nuevo 'Bilbao marca'. Dentro de este modelo urbano y social se asigna un papel a las clases creativas, entre las que se encuentran las artistas y las instituciones artísticas, que forman uno de los ejes vertebradores de esta regeneración urbana, política y social.

Como artista e investigador dispongo de suficiente información tanto del mundo del arte, además de otras disciplinas afines: antropología, urbanismo, etc. que me permiten reflexionar en torno al tema, dado que me encuentro realizando la tesis doctoral en relación a Arte y Transformación urbana en Bilbao desde una perspectiva no colaborativa con el nuevo modelo urbano impuesto.

Como artista que trabaja, estudia, vive y milita en esta ciudad, soy consciente de forma objetiva del sistema artístico, habiendo participado en él, adquiriendo consciencia y posicionamiento a través de mi propia experiencia, además de la adquirida en diferentes contextos relacionados con arte, urbanismo, política... organizados por colectivos diversos en Bilbo. Mi estancia durante tres años (2014 a 2016) en el barrio de San Francisco, en un espacio de trabajo -taller compartido (un antiguo pabellón de almacenaje de vinos y aceite, en la estación de Abando), me permitió relacionar, entender y reflexionar las diferentes redes existentes entre agentes culturales- instituciones-artistas; pudiendo identificar el impacto o las consecuencias que generan tanto en dicho barrio como en el espacio urbano bilbaíno en general. En los últimos años hay un amplio número de publicaciones que estudian las relaciones entre las clases creativas y los procesos de gentrificación en las transformaciones urbanas a lo largo del estado y de otros países.

\section{CIUDAD ESCAPARATE}

Lo que a primera vista sorprende del nuevo modelo de ciudad es la rapidez de los cambios en el paisaje y en el territorio, pero esto no es lo impactante sino la práctica inexistencia de oposición o confrontación por parte de la ciudada- 
nia. El espacio urbano, al ser un producto social es productor-soporte de las relaciones económicas-sociales, de las fuerzas productivas y de la división del trabajo. La precariedad junto a la instrumentalización de las artistas, permite sostener una escena cultural o artística, que sirve como reclamo para vender ciudad. Entonces ¿qué nos pasa por la cabeza tanto al artista que empieza, como del emergente, ...? Una desazón permanente mezclada con una ambición, una dualidad propia de la clase media, unida a un auge del ciudadanismo, que se convierte en el refugio de lo que en su día fueron las izquierdas, que tienden a menospreciar o a tachar de obsoletas la tradición ideológica ${ }^{1}$ de las organizaciones revolucionarias con conciencia de clase. El ciudadanismo abraza los principios democráticos universales con una alta proporción de civismo, participación, democracia, creyendo en una vuelta al estado del bienestar precrisis a través del reformismo dentro del capitalismo voraz.

Es reseñable como las instituciones se valen del entusiasmo (acertado término desarrollado por Remedios Zafra) de las artistas para sostener una escena de arte vasco, altamente precarizada y en muchas ocasiones muy alienada. No es casual que una ciudad creativa como Bilbao, esté provista de infraestructuras culturales, museos, galerías, centros de producción artística, Facultad de Bellas Artes... con sus respectivas becas, concursos, ayudas... como formas de 'profesionalización' de las artistas, que generan un anhelo o esperanza de una empleabilidad a futuro. Ese entusiasmo se instrumentaliza generando mano de obra gratuita para eventos, exposiciones, espectáculos... bajo condiciones de explotación en aras de una visibilidad, que te posibilitara ascender, e incluso llegar a ganar recompensas, en forma de becas, que faciliten en muchos casos un control ideológico, la amnesia o la edulcoración del posicionamiento crítico. Todo esto sería reversible si las relaciones productivas fueran cambiadas o reformuladas dentro de las propias instituciones culturales, superando estas la presión estructural o su instinto de supervivencia, y se negaran a la implantación de las condiciones de mercantilización y espectacularización impuestas por el modelo de ciudad neoliberal.

Es muy difícil encontrar espacios realmente autónomos, la institución engulle todo, y la necesidad de ascenso personal en muchos casos deja de lado la conciencia de clase, o las responsabilidades o repercusión de nuestras acciones, que son queramos o no políticas.

Dado que estas relaciones de producción se dan en lo urbano generan una serie de impactos, problemáticas y conflictos, que afectan al espacio y a las personas. La ubicación de las clases creativas y sus infraestructuras suele 
estar vinculada a procesos de regeneración urbana, es decir se establecen en núcleos urbanos en los que ya existía un tejido social y productivo, desplazándolo y suplantándolo. Generalmente barrios obreros o populares, zonas industriales que acumulan grandes plusvalías espaciales y que se convierten en territorios que explotar.

\section{ARTE Y GENTRIFICACIÓN}

La palabra maldita 'gentrificación'2, aterriza hace ya bastantes años en la capital vizcaína, vinculados a espacios centrales o de la nueva centralidad de la ciudad. Se relaciona directamente con las problemáticas surgidas por el turismo, el arte, la cultura y las clases creativas. Nos centraremos en analizar el impacto que generan los eventos o espacios artísticos y culturales denominados colaborativos, alternativos... en el territorio en el que se desarrollan y si realmente generan confrontación o enfrentamiento o por el contrario permanecen alienados, amparados en consignas ciudadanistas.

Lo que sorprendente a primera vista, es cómo desde la gran mayoría del colectivo artístico y cultural, ven la gentrificación como algo ajeno a ellas, sin asumir responsabilidad como sujeto político dentro de la sociedad. La noción romántica de la autonomía del arte, independiente respecto de la sociedad es falsa, no hay por un lado las artistas creadoras y el sistema que les mantiene por otro.

En la actualidad casi todos los proyectos y prácticas artísticas llevadas a cabo en la ciudad de Bilbao son o han sido financiadas por dinero de público (Ayuntamiento de Bilbao, Diputación de Bizkaia) o privadas (Kutxabank) a través de la financiación de instituciones o asociaciones artísticas o culturales mediante, Fábricas de Creación (Gobierno Vasco) y convocatorias como Ayudas a Asociaciones o Cooperativas de Innovación Sociales (Diputación de Bizkaia). Estas a su vez promueven festivales (Bilbao Art Distric, BLV art, Gau Irekia...), concursos (ArteShop...)o becas de producción o de proyectos culturales (Ideiak Martxan,...), que buscan generar un cuerpo artístico autóctono, en muchos casos low-cost o de pago inmaterial (no económico, reconocimiento social...). La instrumentalización y la alienación del sujeto artista en Bilbao como en otras ciudades-marca es muy fuerte, la crítica por tanto aparece edulcorada salvo honrosas excepciones. La práctica artística bilbaína, o contexto vasco 
se gesta en entornos altamente competitivos e individualistas, sostenida por colaboradoras, becadas y agentes diversos, con una oferta laboral inexistente, escasamente remunerada y en muchas ocasiones con relaciones de producción de explotación a través de 'becas de producción' como por ejemplo las de la Fundación BilboArte que no contemplan salario alguno. La crítica o disidencia por parte de la clase creativa es nula, por más que se camufle o se blinde de comprometido, social, participativo,... el trampantojo dialéctico o 'coherencia ética' no termina de cuajar, dado al conflicto existencial entre la rebelión y la necesidad de ascenso social de las artistas. ${ }^{3}$ El llamado arte social, político o crítico ( ya sea en formato plástico, o en festivales, encuentros,...) no es más que la materialización plástica de la Responsabilidad Social Corporativa (RSC) o también llamada Responsabilidad Social Empresarial (RSE), que consiste a parte del trabajo 'socialmente responsable' o comprometido, la construcción de un capital reputacional (mediático) y en ningún momento buscan subvertir las relaciones de producción capitalistas o impulsar la lucha de clases.

Por eso no es de extrañar que diversas instituciones públicas o culturales de la urbe bilbaína, financien o promuevan eventos, seminarios, charlas... que promuevan este tipo de prácticas "criticas, sociales, políticas y activistas" para institucionalizar y absorber toda disidencia, bajo un control ideológico y de propaganda ciudadanista (el ciudadanista no es de izquierdas, ni de derechas...)

En lo que concierne al espacio urbano, la zonificación y centralización de la práctica artística, no es casual la gestión del territorio y del urbanismo por parte de las instituciones no es una cuestión técnica, sino política. La transformación del paisaje bilbaíno, para invertir y atraer capital, viene unida al cambio o destierro de usos o personas de determinadas áreas urbanas que generen beneficio. Esto es llamado gentrificación, que reconfigura las relaciones de clase a través del urbanismo, es la representación espacial de capitalismo y se vehicula mediante diferentes estrategias de consumir el espacio, como la especulación inmobiliaria, el turismo o relacionado con cuestiones más subjetivas como la identidad, lo popular, lo multicultural, etc.

Para llevar a cabo este proceso, en una ciudad cuyo símbolo impuesto es el museo Guggenheim, el papel del arte y la cultura es vital, y por tanto recae una gran responsabilidad sobre la clase creativa a la que pertenecen las artistas. La necesidad de nuevos escenarios que transformar para expandir el nuevo Bilbao 'cultural', necesita ocupar nuevos espacios y barrios, que en una etapa previa a la 'regeneración' carecían de algún modo de vida, que eran 'culturalmente moribundos' y son revitalizados gracias a una intrépida y pionera clase 
creativa ${ }^{4}$. El desembarco fue en el barrio abandonado y estigmatizado de San Francisco, Bilbao La Vieja y Zabala, pero no olvidándonos zonas industriales 'obsoletas' como Zorrotzaurre, o la Ribera de Deusto. La clase creativa no ha llegado porque sí, la preparación del entorno a través una serie de medidas institucionales como la creación de infraestructuras culturales en el barrio San Francisco y Bilbao la Vieja (Bilboarte, Museo de Reproducciones, Bilborock, residencias de estudiantes de la UPV/EHU Blas de Otero). En la 'isla creativa' de Zorrotzaurre, apoyando 'espacios creativos' (ZAWP, Espacio Open...) junto a las iniciativas privadas en antiguos edificios industriales comprados y rehabilitados con dinero público como DigiPen Institute of Technology Europe-Bilbao (Universidad del videojuego) o el Centro Superior de diseño Kunsthal. Además de ayudas económicas para establecer proyectos culturales alternativos o cooperativas de iniciativa social que dinamicen las zonas a transformar, como las existentes en el barrio de San Francisco (Sarean, Wikitoki, Okela, ...)

Obviamente la imagen del barrio degradado de hace más de una década, va quedando relegada a un segundo plano y cada vez se ve como un escenario más atractivo donde las personas vinculadas a la clase creativa u hosteleros abren locales y desarrollan su práctica artística, el barrio ha sido explotado una vez más por su valor promocional, un punto de interés turístico, cultural o social exótico y peligroso.

Lo que sorprende es la ausencia de lucha en contra de este modelo impuesto, y la ausencia de asumir responsabilidades o posición respecto al impacto de las prácticas artísticas en estos barrios, hiperatrofiados de festivales, espacios alternativos, acciones o intervenciones artísticas en el espacio urbano. La edulcorada crítica existente hacia la gentrificación es sorprendente, ya que las artistas o agentes culturales se muestran como víctimas y no como parte del problema. Pero hoy día la doble moral se cura, a través de una relación directa de las prácticas artísticas con la comunidad, investigando o produciendo trabajos participativos, recopilando 'capital reputacional' y en ocasiones una remuneración económica precaria, que debido a la corta duración de estas propuestas no tienen para ellas causas y menos una consecuencia o responsabilidad ideológica. La artista por tanto nuevamente no puede comprender las relaciones de producción en las que esta inmersa, "lo que parece suceder así fuera de la ideología (en la calle) pasa en realidad en la ideología. Lo que parece suceder en realidad en la ideología parece por tanto que sucede fuera de ella. Por eso aquellos que están en la ideología se creen fuera de ella (...) Se sabe muy bien que la acusación de estar en la ideología vale siempre para los demás, nunca para uno mismo" (Althusser 1968). 
Esta intensificación de las conflictividades urbanas, han venido precedidas de un auge del interés por el espacio urbano, por un lado como búsquedas de emplazamientos en los que desarrollar un proyecto artístico, cultural vinculado a un territorio (generalmente barrios populares o obreros, buscando una participación), y la actuación directa en el espacio urbano a través de dispositivos, muralismo, carteles... (con ubicaciones pensadas en pro de una máxima visibilidad). Muchas de estas propuestas se podrían encuadrar en un cierto arte crítico $^{5}$, político, activista o social que busca analizar y comprender las estrategias de control y exclusión social alimentando la consciencia crítica del espectador, vinculándose con la especificidad de lugar donde se desarrollan con la noción de entorno y participación, orientado a la búsqueda de convertir las prácticas artísticas como herramienta de transformación social. El antropólogo Manuel Delgado, utiliza el término 'Artivistas' para reflexionar sobre estas propuestas plásticas y la estetización de las practicas activistas. Todo esto ha desencadenado efectos paradójicos y cuestionables, muchos de ellos relacionados por la falta de confrontación directa o ausencia crítica, unido a una institucionalización hegemónica de la mayoría de este tipo de prácticas artísticas, afectando también a eventos culturales o espacios creativos que se muestran como alternativos...

Colonialismo, paternalismo, apropiacionismo e idealización de la pobreza, no se busca la confrontación sino la estetización por tanto, la higienización de espacios urbanos olvidados y degradados por la institución. El componente político queda desarticulado en pro de valores ciudadanistas y complacientes con las instituciones que permiten y financian dichos trabajos. El impacto que generan dichas prácticas en el espacio urbano que colonizan es palpable, ganando el interés y el acercamiento de personas ajenas al barrio y a sus conflictividades, a la vez de contribuir a la significación del espacio, en pro de un valor añadido a la hora de las operaciones inmobiliarias. Generando un turismo, a modo de safari urbano que explota estos espacios en la búsqueda de lo real, de lo obrero, por personas totalmente desclasadas y que hace tiempo que rechazaron las ideas revolucionarias o de conciencia de clase. Recicladas en el nuevo refugio de lo que fue la izquierda combativa, los ciudadanistas permanecen confinados en una especie de élite de clase media burguesa que aspira a unas mejoras sociales y espaciales en el entorno urbano, confiando en los procesos participativos, el artivismo y una redefinición más equilibrada del capitalismo y de la producción neoliberal del espacio urbano. La desvinculación con las problemáticas reales de los barrios obreros es palpable, en una encerrona constante en la búsqueda por atraer a los vecinos originarios, hacia las aspiraciones de una "alta cultura", unos valores o derechos cívicos democráticos promovida por estas artistas o colectivos. Buscando la acumulación 
de un capitalismo reputacional, a través de sus proyectos activistas y participativos, que les permita legitimarse políticamente permaneciendo al margen de cualquier tipo de posicionamiento ideológico o de acción directa real.

Es necesario por tanto una revisión de lo que consideramos como crítico o político dentro de las prácticas artísticas en la urbe de Bilbao, y ser conscientes de que papel juegan las prácticas artísticas y culturales en la construcción y consolidación de este nuevo modelo de ciudad creativa neoliberal. La posibilidad de una disidencia pasa por romper con el sometimiento y dar una respuesta política desde fuera de sus instituciones, despedazar las estructuras hegemónicas y dejar de ser cómplices. Buscar una confrontación y una ruptura frente a las relaciones productivas de explotación, generar solidaridad y apoyo mutuo dentro y fuera del colectivo, repensar nuestras formas de relacionarnos y trabajar en y con el espacio urbano, siendo conscientes de nuestro impacto en el entorno social.

En la actualidad colectivos sociales y organizaciones políticas con conciencia de clase de la población bilbaína ya hacen frente a este modelo urbano impuesto, es hora de trabajar juntas para redefinir y romper la alienación de las artistas. Es hora de encender Bilbo.

\section{Referencias}

Althusser, Louis. (1968) 2008. La filosofía como arma de la revolución: Ideología y aparatos ideológicos de Estado. Traducción directa del francés, Oscar del Barco y Enrique Román. México DF: Siglo XXI

Amarós, Miquel. 2006. "La urbe totalitaria”. Ekintza Zuzena 33

Colectivo DesFace. 2012. Contra el arte y el artista. Santiago de Chile: Libros Desface

Delgado Ruiz, Manuel. 2016. Ciudadanismo: La reforma ética y estética del capitalismo. Madrid: Catarata

Larrea Larrondo, Andeka \& Garikoitz Gamarra Quintanilla. 2007. Bilbao y su doble ¿Regeneración urbana o destrucción de la vida pública? Bilbo: Martxoak

Lefebvre, Henri. (1974) 2013. La producción del espacio. Prólogo de Ion Martínez Lorea; introducción y traducción de Emilio Martínez Gutiérrez. Madrid: Capitan Swimg

Lefebvre, Henri. 1976. Espacio y política. Traducción de Janine Muls de Liarás y Jaime Liarás García. Barcelona: Peninsula

Marx, Karl (1844) 1968. "Introducción a la crítica de la filosofía del derecho de Hegel”. En Filosofía del Derecho, Georg Wilhelm Friedrich Hegel; traducción especial por la doctora Angélica Mendoza de Montero, $5^{a}$ ed. Buenos Aires: Claridad 
Marx, Karl. (1850) 1999. "Circular del Comité Central a la Liga Comunista". Marxist Internet Archive Sección en español. https://www.marxists.org/espanol/m-e/1850s/50_circ.htm

Observatorio Metropolitano de Madrid. 2015. El mercado contra la ciudad: Globalización, gentrificación y políticas urbanas. Madrid: Traficantes de Sueños

Rancière, Jacques. 2005. Sobre políticas estéticas. Traducción de Manuel Arranz. Barcelona: Universitat Autónoma de Barcelona

Rosler, Martha. 2017. Clase cultural: Arte y gentrificación. Traducción, Gerardo Jorge; introducción, Stephen Squibb. Buenos Aires: Caja Negra

Salazar, Carlos. 2017. Antología de textos críticos (2004-2013). Cali: Bis Abril

Smith, Neil. 2012. La nueva frontera urbana: Ciudad revanchista y gentrificación. Traducción, Verónica Hendel. Madrid: Traficantes de Sueños

Zafra Alcaraz, Remedios. 2017. El entusiasmo: Precariedad y trabajo creativo en la era digital. Barcelona: Anagrama

\section{Notas}

1 "La historia no hace nada a medias y atraviesa muchas fases cuando quiere conducir una vieja forma social a la tumba. La última fase de una forma histórica es su comedia (...) ¿Por qué esta marcha de la historia? Para que la humanidad se separe alegremente de su pasado" (Marx [1844] 1968).

${ }^{2}$ La inversión de capital, transformación o regeneración del paisaje urbano, el cambio o destierro de usos, personas de determinadas zonas de las ciudades y su sustitución por usos que generen mayor beneficio económico, todo esto es gentrificación.

${ }^{3}$ La pequeña burguesía democrática está muy lejos de desear la transformación de toda la sociedad; su finalidad tiende únicamente a producir los cambios en las condiciones sociales que pueden hacer su vida en la sociedad actual más confortable y provechosa (Marx 1850).

${ }^{4}$ La idea de pioneros urbanos, nos recuerda a las ideas colonialistas y a los efectos que causaron en esas comunidades nativas.

5 "El arte crítico, en su fórmula más general, se propone hacer conscientes los mecanismos de dominación para transformar al espectador en actor consciente de la transformación del mundo" (Rancière 2005, 34). 